\title{
IV. Alutiz̨en.
}

Erweiterung der Seiftungen des Dereins "waldheil" ju Keudamm.

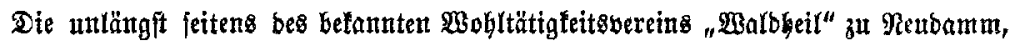

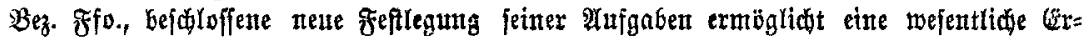

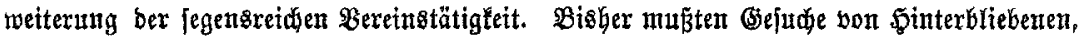
beren Ernäbrer na bem 1. Februar 1899 werftorben war, whne Mitglied bes "Nalb=

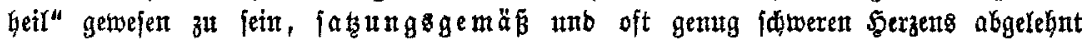

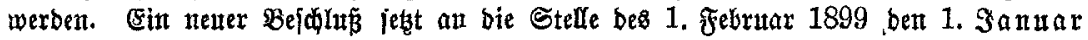
1920 unb madit bamit alfe in Rot befinbliden $\mathfrak{W i t m e n}$ unb 5interbliebenen bon Frorft=

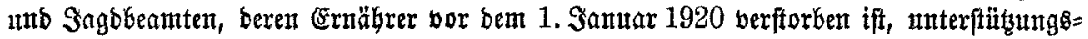
berechtigt. "Walbhetl ${ }^{\prime}$ fann fid in Butunft nummehr, forveit fetne Mittel es ingettowie julaffen, and ber vielen binterblebenen von srieg teilnebmern ber gränen Farbe bejonders andehmen.

Die erweiterten Biele bes Bereins exforbern ăl ihrex Durăfübrung naturgemäp

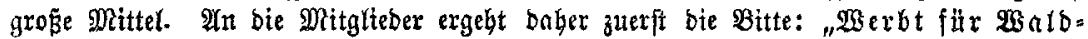
beil!" Die fegensreidien Biele bes Bereins eitterjeits nnb anbererjeits bie Sorge $1 \mathrm{~m}$

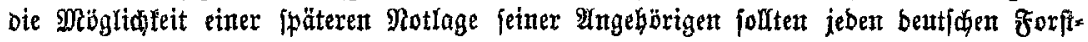
unb Sagbbeamten veranlafien, bem "Balbheil" beizutreten. Die zoeite Bitte lautet bann: Fübrt alfe \$ilfsbebürtigen ber gränen Farbe bem "Walbbeil" zu! Retne in Not befinditue Förfterwitwe ober Förftertodter, feitte Förfterwaifen barf e fernerbin in Dentidiand geben, benen ntwit Renttnis gegeben worben ift, baj ber "Walbbeil" ftith threr Mot gern und allezeit Gilfretch annebuten wirb.

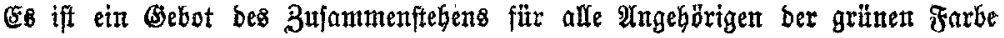

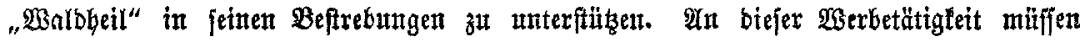

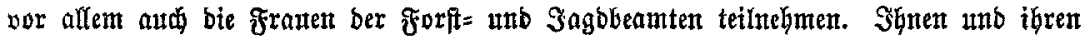

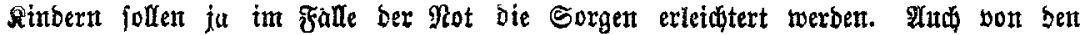
alten Fremben unb Gönnern bes "WalbGeil" wirb bie oft ein Mieniobentulter Gindurch betwährte Trente wotter erfoffit.

So helfe jeber mit, bas bie neuen Biele zut sinem Maxffetn in ber Entwioflung

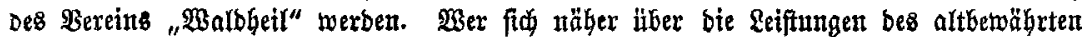

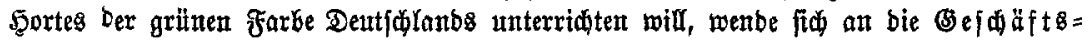

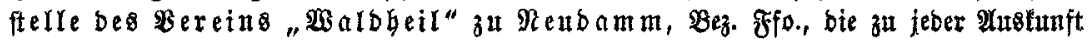
gern bereit iff.

\section{Perjonalnad̨rįhtert. $\left.{ }^{1}\right)$}

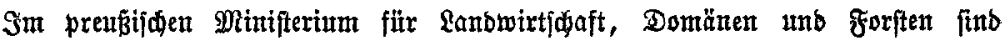

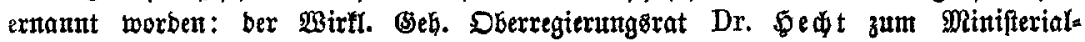

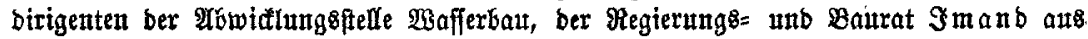

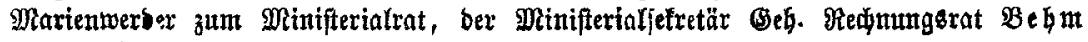
zum Regienungerat.

1) Mitgeteilt vom Preffebienft bez Minifteriums für \&anbwirtføaft, Domänen unt Forften. 